Revista STUDIUM N. ${ }^{\circ} 2$ - 3, 2001 (pp. 61-73)

\title{
LA CASA HACIENDA PUNCHAUCA: ANÁLISIS ARQUITECTÓNICO
}

Dr. P. Antonio SAN CRISTÓBAL

\section{La distribución de la planta}

El núcleo central de la casa-hacienda Punchauca conserva, aunque con deteriores, materiales de mucha consideración; las estructuras de dos grupos habitacionales, entre los que se intercala un amplio patio central, y la diminuta capilla adosada a la residencia principal. Aunque este conjunto parece haber conformado originariamente un rectángulo completo, se observa la falta de un sector de construcciones colocado en posición longitudinal, al fondo del lado derecho del rectângulo, mirando de frente a la fachada principal. Y cabe suponer que también falta otra sección de construcción en el lado izquierdo alargado del rectángulo que cerraría el patio por ese sector.

Se emplea en esta casa-hacienda el sistema constructivo de las crujias alargadas, característico de las viviendas virreinales limeñas. Consiste la crujia en un espacio alargado delimitado por dos largos muros paralelos, que se puede subdividir internamente en aposentos más pequeños mediante muros transversales tendidos desde un muro longitudinal al otro. Las crujias de la construcción virreinal alcanzaban en las casas de vivienda una anchura que no sobrepasaba nunca las siete varas y media, es decir un equivalente máximo aproximado a 6.40 metros. Las habitaciones formadas por la subdivisión de la crujía solian tener planta rectangular con el lado largo alineado en la dirección de la crujía, y el lado corto correspondiente a la anchura de la misma crujía.

El sistema constructivo de las crujías facilitaba el tendido de las cubiertas sobre los aposentos. Se formaban las cubiertas por vigas gruesas de sector rectangular denominadas cuartones: éstos se colocaban asentados perpendicularmente por el lado más largo. Los cuartones se tendian de un muro longitudinal al otro, dejando una separación uniforme de cuartón a cuartón de media vara, es decir, aproximadamente unos cuarenta centímetros. El número de los cuartones que cubrían cada habitación 


\section{Dr. P. Antonio SAN CRISTÓBAL}

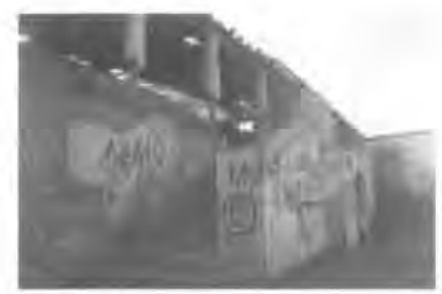

dependía de la longitud de los cuartones para cubrir los aposentos de una misma casa, ya que todas las crujías eran aproximadamente iguales en su anchura.

Para la distribución de la casa-hacienda Punchauca, se adoptó la disposición de las crujías según los dos grupos habitacionales de que se compone el edificio. El sector principal, destinado a la residencia de los propietarios, se compone de tres crujías acopladas en forma de rectángulo que deja un lado corto abierto. Hay una crujía frontera que ocupa todo el frente principal de la casa-hacienda, a la que se antepone el corredor cobijo sustentado por columnas toscanas de madera. En realidad, este corredor no forma parte inteligente de la crujía frontera, sino que se antepone a ella a modo de cobertizo para proteger las puertas y ventanas contra la intemperie del sol y de la escasa lluvia. La crujía frontera está conformada por los dos muros paralelos alargados en los que se abren los vanos de las puertas y de las ventanas. De igual modo, tampoco forma parte de la crujia frontera la pequeña capilla y su sacristía adjunta, que corresponden a una construcción posterior y sobreañadida.

En los extremos de la crujia frontera se acoplan otras dos crujías perpendiculares que actualmente han perdido la parte más adelantada, pero que en otro tiempo llegaron a cerrar los lados laterales del patio en forma de U. Esta disposición topográfica de las tres crujías era común en las casa de morada más importantes de Lima, y se conserva dispuesta en el palacio de Torre Tagle, la Casa de Pilatos, la Casa de la Riva, la de la sede del Instituto Riva Agüero, etc.

Las tres crujias de esta casa-hacienda han quedado exentas en ambos muros laterales; y por consiguiente se pueden abrir vanos de puertas y 
ventanas en los dos muros básicos de cada crujía. Se trata de una disposición típica de las casas-hacienda, porque ellas no tienen casa adosadas en alguno de sus flancos. Contrasta la apertura de vanos en ambos muros laterales de las crujías perpendiculares a la frontera en las casas urbanas de Lima, por cuanto en estas últimas el muro exterior de tales crujias perpendiculares estaba necesariamente ciego en toda su longitud, ya que servía de pared medianera o divisoria con la casa vecina.

El segundo núcleo de habitaciones, que se encuentra situado al fondo de la planta, está compuesto de tres crujías de igual longitud y distribuidas de modo contiguo en sentido paralelo por el lado más alargado de cada rectángulo. Estas tres crujias paralelas delimitan el lado corto en el rectángulo de la planta al final del patio, $y$ forman un sector paralelo al de la crujía frontera aunque más corto y más profundo que ella; entre uno y otro sector paralelo se encuentra delimitado el patio central de la casa-hacienda. La crujía exterior de las tres, situada en el lado izquierdo, está subdividida en dos aposentillos mediante un muro transversal en cuyo centro se abre una puerta. Se abren vanos de puertas y ventanas en todos los muros de las tres crujías paralelas, tanto en los muros alargados como en los cortos.

Aunque parece que estos dos núcleos básicos de habitaciones debian cerrar los cuatto lados del patio rectangular, siguen la tradición de las casas limeñas virreinales, que dejan siempre un callejón abierto en una de las esquinas del patio primero para servir de vía de comunicación entre el patio principal y el segundo patio. Este callejón de Punchauca está abierto en el lado izquierdo del patio, al fondo del mismo, $y$ discurre entre el final de la crujia perpendicular y el frente del mismo, y discurre entre el final de la crujia
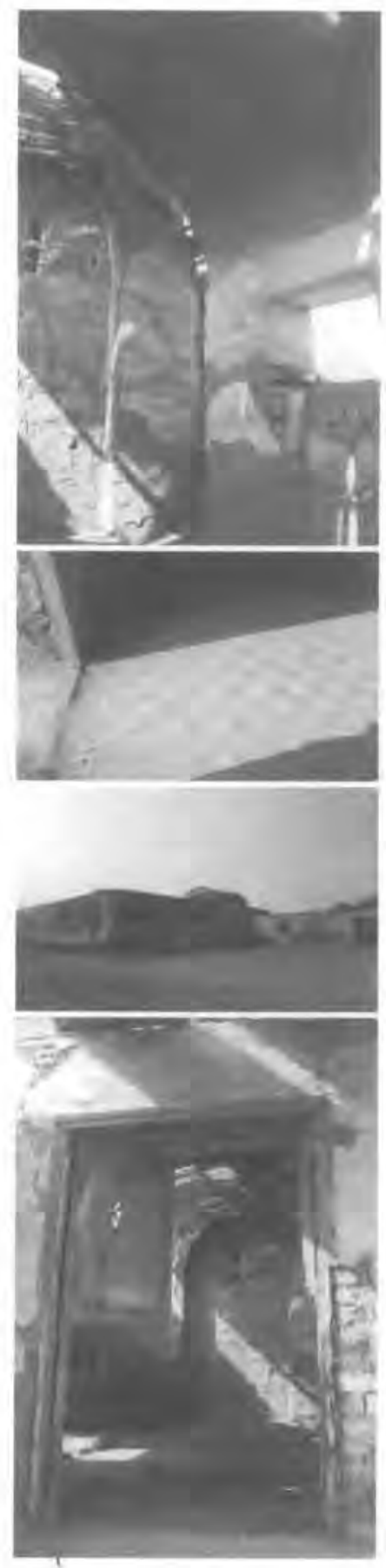

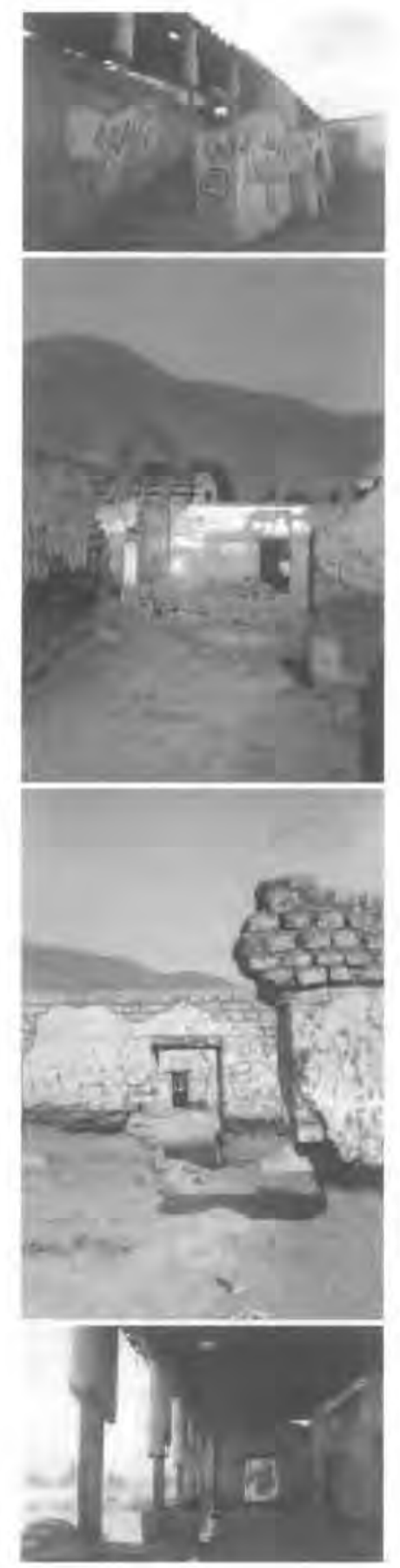

perpendicular y el frente de la primera crujia de las tres paralelas en este mismo lado. Servia este callejón para la entrada a las tres crujías paralelas del fondo desde el exterior a través de una puerta lateral a la que se ingresa por una escalera externa paralela a la crujía perpendicular y adosada a ella.

En el estado actual de las ruinas no se puede discernir con seguridad si los dos núcleos habitacionales, el frontero de las tres crujías en U y el del fondo con las tres crujías paralelas, estuvieton incomunicados o bien se abrían libremente hacia el patio interior. Se pueden observar los restos de lo que parece haber sido un muro muy delgado por el que se prolongaba el callejón de entrada hasta el extremo opuesto a la escalerilla de ingreso. Por el escaso grosor de este presunto muro divisorio, que no corresponde a la construcción virreinal de adobes, se puede suponer que no pertenecía a la construcción primera de la casa hacienda, sino que fue introducido muy tardíamente para separar dos viviendas independientes y dotadas de entrada distinta. Lo más conforme al sistema de la distribución topográfica en la casa virreinal era que todos los aposentos situados en los cuatro lados de un mismo patio tuvieron libre comunicación abierta hacia ese mismo patio central, aunque habitaran distintas familias en unos u otros aposentos.

\section{Las fachadas}

Constituyen las fachadas unó de los componentes estructurales más identificatorios de los edificios virreinales. Para analizar las fachadas de la casa hacienda Punchauca, es conveniente tener en cuenta que todo el rectángulo del conjunto habitacional está alzado sobre una plataforma a cierțo nivel más elevado que el suelo exterior a la propia casa hacienda. 
Es posible que mediante esta elevación de la casa en la plataforma pretendieron preservar los muros de adobe contra el debilitamiento con que los hubiera erosionado la humedad de los desbordes de las acequias de regadío o de limpieza. La elevación de la casa hacienda sobre la tal plataforma por encima del terreno de las tiertas circundantes, obligó a incorporar algunas escaleras para el ingreso de las habitaciones en todos los lados donde se habría puertas de ingreso al rectángulo elevado. Estas escaleras antepuestas en el frente de las puertas, constituyen parte integrante de las fachadas externas de la casa hacienda Punchauca.

La construcción de la actual capilla y su sacristia en el lado derecho de la fachada principal, modifica profundamente este sector de la fachada de frontera, tanto en la conformación de la fachada misma como en la planta de la crujía frontera; además desde que discontinuo la galeria del corredor cobijo, que anteriormente abrazaba de modo continuo en ángulo recto este sector de la crujía frontera.

Integran la fachada principal tres componente parciales: el primero es la escalera de doble rampa, antepuesta a la galería y en sentido paralelo a ella; el segundo consiste en el sector ahora remanente de la galería de corredor cobijo; y el tercero está dado por el frente lateral de la capilla y la sacristía; las dos escalinatas frontales terminan en un cuerpo central elevado a un mismo nivel que la galería del corredor, y que está situado enfrente de la puerta de la sala. Debajo de este cuerpo alto horizontal se alberga un aposentillo pequeño con su puerta para guardar utensilios de limpieza pequeños. En la parte baja la escalera doble se reitera el friso de grandes rectángulos ochavados que adorna el cuerpo bajo de la galería. Ocupaban inicialmente la escalera de la puerta de la sala la posición de eje central de la fachada, formándose dos cuerpos
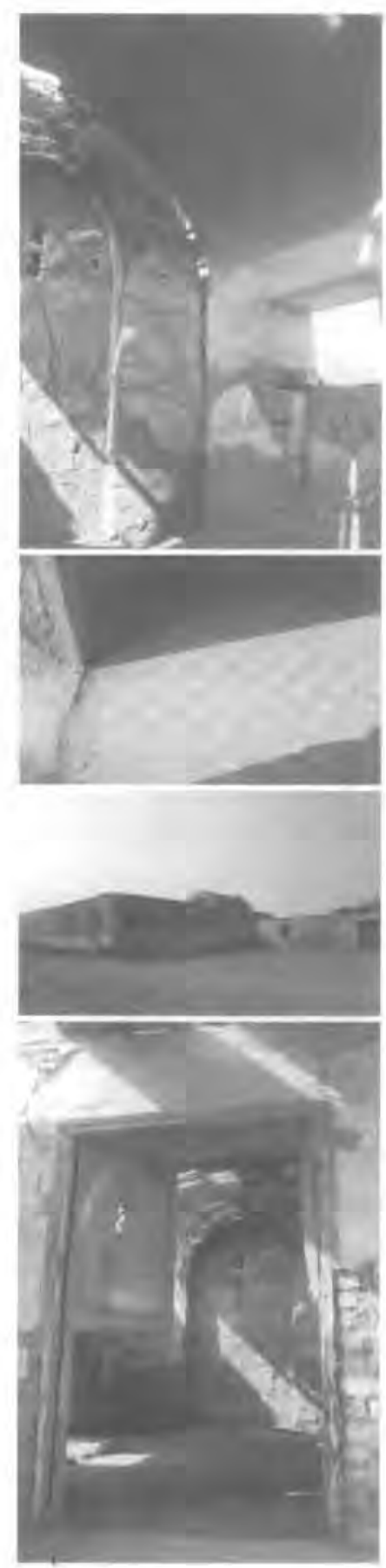


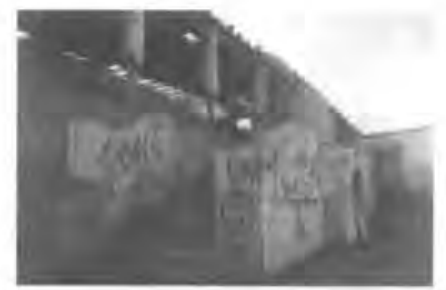

simétricos a los lados; en cada cuerpo se habría el mismo número de vanos laterales; pero la incorporación de la capilla y su sacristía ha desarticulado en un tiempo posterior aquella simetría frontal de la casa hacienda.

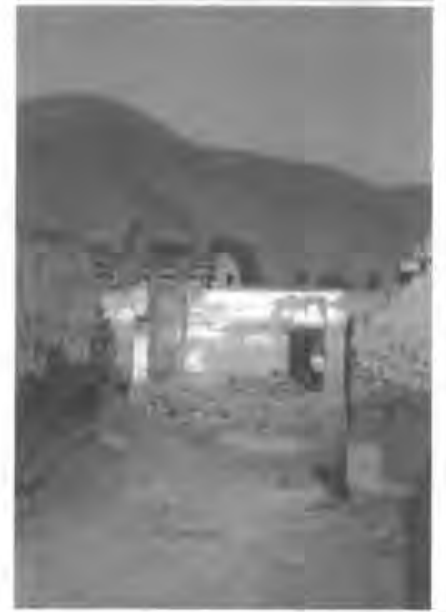

La galería delantera está cubierta con un corredor cobijo. Lo denominamos corredor cobijo; porque la plataforma que lo recubre no sirve para el transito sobre ellos, sino para cobijar esa galería. Sustenta actualmente el sector remanente de corredor cuatro columnas toscanas exentas con notorio énfasis en el fuste; y dos medias columnas adosadas a los muros en los extremos sobre la capital de las columnas que no llega a conformar una zapata propiamente dicha, asienta una viga madre alargada en la que se apoyan los extremos salientes de los cuartoncillos con la que se cubre la galería. Antes de incorporarse la galería y su sacristía, la galería acogía a los vanos de los aposentes fronteros dispuestos con armoniosa simetría a los dos lados de la escalera y de la puerta de la sala. Pero en la actualidad, la galería y los vanos del muro del fondo quedan desplazados en el lado izquierdo de la fachada frontera, pues el otro lado de la fachada opuesto ofrece un aspecto distinto.

En el lado derecho de la fachada principal destaca liso y desnudo el muro lateral del conjunto capilla-sacristía, elevado a la misma altura que el sector de la galería; y por encima del muro de la capilla sobresale el extradós de la pequeña bovedilla. Solo se abren en este muro lateral dos ventanas pequeñas de la capital y de la sacristía, que se alzan en lo alto de los muros según la práctica tradicional en las iglesias virreinales.

La fachada lateral en el frente derecho de la casa hacienda muestra el mismo rompimiento discontinuo introducido por la construcción tardía del conjunto 
capilla-sacristía, en este ángulo de la casa. Se descompone esta fachada lateral en tres sectores: el muro testero de la sacristía con una pequeña ventana en lo alto; el sector remanente de la galería en ângulo recto; $y$ el muro externo longitudinal de la crujia perpendicular a la crujía frontera de la casa. El sector de la galería esta conformado por un corredor cobijo más simple que el de la fachada principal, pues sustenta la viga madre tres delgados pies derechos desprovistos de zapatas. La pequeña galería permanece ahora en una posición marginal respecto de toda la estructura de la casa hacienda. Reiteremos nuestro convencimiento de que anteriormente este sector de galería constituye el lado derecho de la gran galería unitaria extendía en ángulo recto. La capilla se introdujo en el vértice de la gran galería continua angular, y la ha fragmentado en los dos sectores distanciados ahora remanentes. Puesto que este sector lateral de galería ha quedado desvinculado del sector frontero a la casa, se ha hecho necesario añadir una escalerilla para la súbita independiente de la otra escalera doble.

La fachada lateral en el lado izquierdo del rectángulo de la planta muestra la austera sobriedad de un muro alargado, y continuo en el que se abren algunos vanos de ventanas correspondientes a los dos sectores habitacionales antes señalados. Solamente destaca en este muro la puerta de entrada al callejón que conduce al segundo núcleo de los aposentos. Se antepone a esta puerta una escalera de una sola rampa colocada también en sentido paralelo al muro alargado.

La cuarta fachada que pudiéramos denominar del muro testero de la planta rectangular, manifiesta al exterior la estructura constructiva del segundo sector habitacional. Apatecen en lo alto del muro las tres ventanas pequeñas una por cada crujia paralela; y además se anteponen al muro testero cuatro pilares a
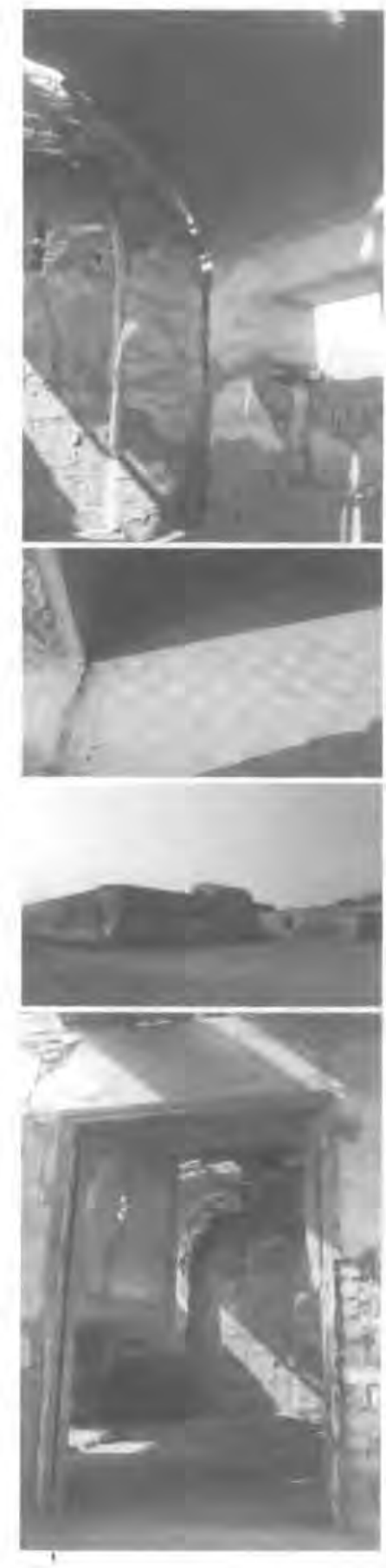


\section{Dr. P. Antonio SAN CRISTÓBAL}

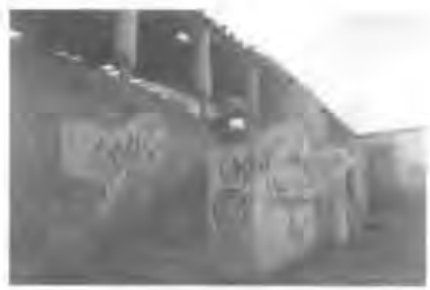

modo de contrafuertes para consolidar los cuatro muros longitudinales que delimitan las tres crujias paralelas.

En su conjunto esta casa hacienda de Punchauca muestra un aspecto variado de noble sencillez, pero muy expresivo de la arquitectura virreinal propias de las casas señoriales del campo. Contrasta este aspecto con el de las casas urbanas, porque deja visible los cuatro frentes de las fachadas en el rectángulo construido; mientras que en la ciudad las casas solo muestran la fachada de calle. El segundo elemento que diferencian las casas hacienda respecto de las casas urbanas consiste en la galería del corredor cobijo antepuesta al muro de los pies. En las casas limeñas del siglo XXIII, el corredor cobijo se antepone en la sala atravesada en el patio enfrente del arco del zaguán, nunca delante de la fachada de la calle. Todo el conjunto de la casa hacienda resalta además por estar asentado sobre una plataforma elevada que impone la necesidad de colocar escaleras frontales párale acceso a los aposentos. Algunas casas urbanas en la escuela arquitectónica en la ciudad de Trujillo se alzan sobre plataformas al igual que la casa hacienda Punchauca.

\section{Distribución interna de la casa de vivienda}

Analizamos la distribución de los aposentos en la casa-hacienda de Punchauca con referencias al contexto del modo como se distribuian las habitaciones en la casa urbana virreinal. De este modo destacamos con mayor nitidez las características peculiares de esta casa-hacienda. También existe en la casa-hacienda una crujía frontera de semejanza de la que lindaba con la calle en las casas urbanas. Pero aparece inmediatamente el contraste en la conformación de una y otra tipología de crujías que 
cuentan las casas urbanas de vivienda con un zaguán abierto por ambos frentes, que ocupa el centro de la crujía frontera; $\mathrm{y}$ a los lados del zaguán suele instalarse la carrocera, una tienda $o$ algún aposento secundario para habitación del escudero o portero. A diferencia de ello, la crujía frontera de la casa-hacienda está ocupada en toda su longitud por habitaciones de uso familiar, y naturalmente carece del zaguán libre intercalado entre ellas.

La crujía frontera de Punchauca aparece actualmente integrada por dos aposentos muy desiguales de dongitud: el uno corto $y$ el otro desmesuradamente largo; pero es posible que antes de incorporarse en el sector frontero, la capilla y su sacristía, esa crujía tuviera una división triple, con un aposento más amplio en el centro, y otro aposento menor a cada lado del aposento central, semejante al que ahora existe en el lado izquierdo. Esos aposentos laterales, que existieron antes de la actual capilla, mantendrían puertas de comunicación con los aposentos continuos de las dos crujias perpendiculares, tal como ahora se observa.

Supuesta esta distribución topográfica de los aposentos en la crujia frontera, podemos interpretar que el aposento central más amplio correspondería a la sala; y además que cada uno de los aposentos laterales menores tendría este uso: uno de ellos como cámara de dormir con su adjunta recámara; y el otro como "escritorio" o despacho donde el dueño de la hacienda administraba su negocio agrícola. En la crujía perpendicular del lado izquierdo, que parece haber sido la de mayor longitud, pudo haber existido otro conjunto de cámara-recámara que posiblemente fuera utilizado para alojamiento de huéspedes.

La galería del corredor, cobijo antepuesto en el lado extremo izquierdo de la crujía frontera, sugiere esta interpretación. Puesto que la casa-hacienda carece de otra crujía atravesada en el patio a cierta distancia de
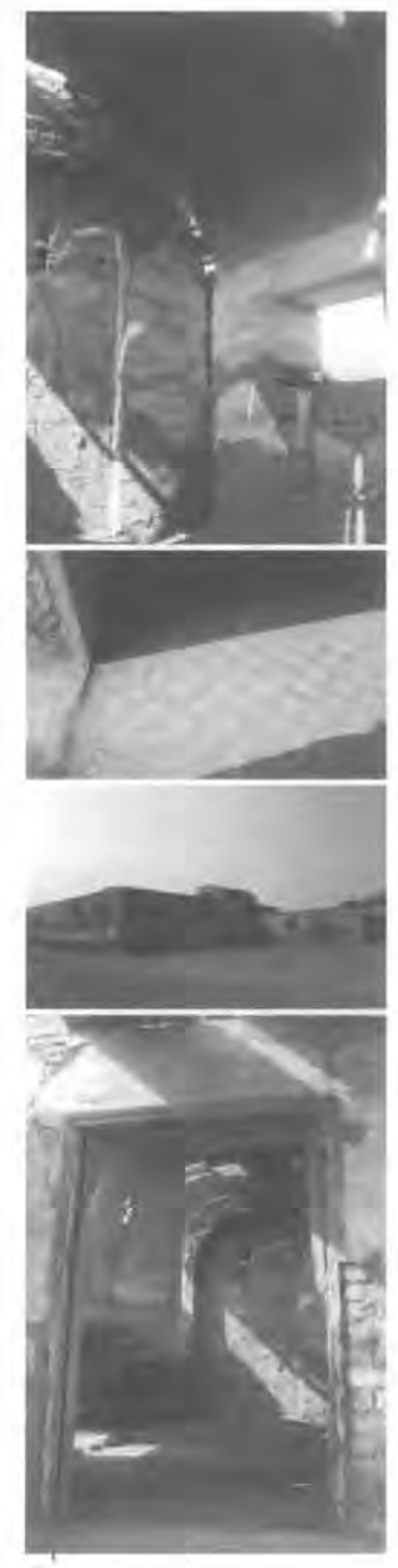

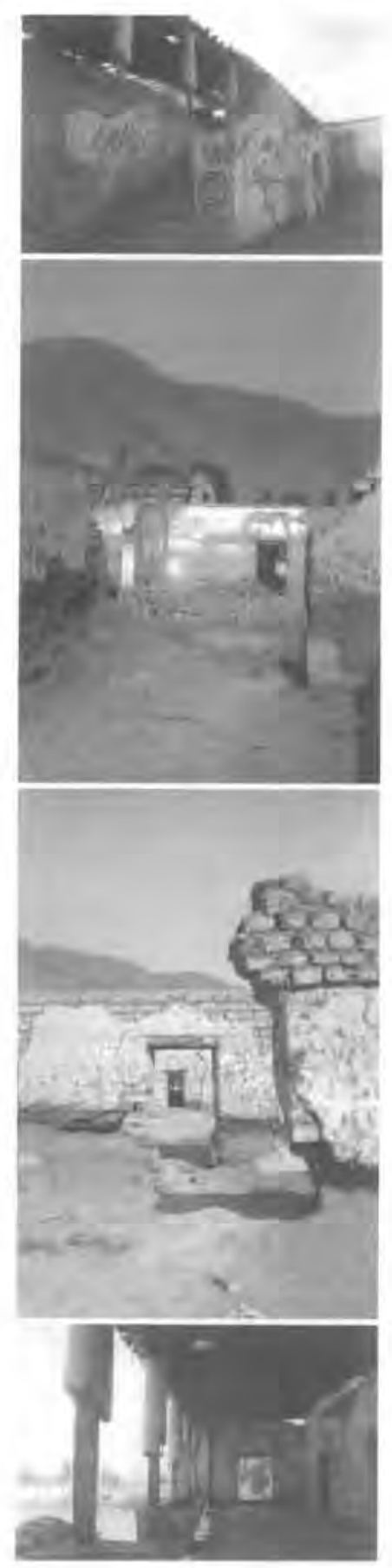

la crujia frontera y en posición paralela a ella, pareciera como que la casa-hacienda hubiera prescindido de todo el amplio sector integrado por la crujía del zaguáncarrocera-tienda y del patio tan característico de la casa urbana limeña; y comenzará a desplegarse hacia el inferior del solar a partir de esta segunda crujía paralela en la casa urbana en la que está colocada la sala con su corredor cobijo antepuesto. Resulta que el patio principal de la casa-hacienda Punchauca equivale en realidad al segundo patio de las casas urbanas limeñas que se extiende detrás de la crujía donde está situada la sala.

Esta casa-hacienda de Punchauca localiza la sala en una crujía simple alargada. También difiere esta conformación respecto de la que es usual en las casas virreinales de Lima. A la crujía de la sala se yuxtapone otra crujía paralela para la cuadra de estrado, formando ambos aposentos una doble crujía sala-cuadra atravesada entre los patios.

Integran también la planta de esta casahacienda las tres crujias paralelas situadas en el fondo del patio central. Presentan ellas la conformación un tanto anómala de incorporar la puerta de entrada a los aposentos en el muto corto del rectángulo, pues la norma común en las casas de vivienda urbanas es la de abrir la puerta de entrada a los aposentos y una ventana, si lo permite la longitud de la habitación, en uno de los dos muros alargados del rectángulo. Pero resulta que al disponer las tres crujías en paralelo alargado no quedaba otta alternativa posible para situar las puertas de los aposentos, que abrirla en uno de los lados cortos del rectángulo que quedara libre.

Este análisis topográfico de la planta de Puchauca no permite conocer cual ha sido el destino asignado a estos tres aposentos del fondo del patio. Posiblemente hayan servido como vivienda del capellán de la hacienda, del administrador o de la 


\section{LA CASA HACIENDA PUNCHAUCA: ANALISIS ARQUITECTONICO}

cocinera, De todos modos, constituyen unas cdificaciones anómalas en relación a los aposentos usualmente habitables en las casas virreinales de Lima.

\section{El conjunto de capilla y sacristía}

Están incorporadas la capilla y su sacristía en el ángulo derecho de la fachada principal, a manera de un cuerpo autónomo, al que se ingresa por el lado derecho del corredor cobijo frontero. Los dos ambientes pertenecen a una sola crujia alargada, en la que se ha introducido un muro transversal para separar la capilla de la sacristía, dejando una puertecilla de comunicación entre ellas. Difieren estos dos espacios consecutivos porque cada uno se cubre con distinto tipo de cubierta. Destaca esta crujia capilla-sacristía por su mayor anchura respecto de todas las otras crujías de la casahacienda.

En lugar de construir una capilla independiente y separada de la casa-habitación, prefirieron adjuntar adosada a las habitaciones del primer conjunto. Fue acomodada esta nueva crujía sobre una parte del corredor cobijo antepuesto a la fachada principal y el ala lateral derecha. De este modo, el conjunto de capilla-sacristía rompió la unidad continua del corredor cobijo, que ahora aparece fragmentado en dos sectores independientes, distanciados y antepuestos a distintas fachadas.

Suponemos, pues, que la crujia de capillasacristia fue añadida a la casa-hacienda en una época posterior a la construcción del edificio de las habitaciones. Aunque sigue la alineación del eje frontal del corredor, esta crujía sin embargo, tiene mayor anchura que el mismo corredor, lo que se observa porque en el lado de la casa invade un espacio interno de la sala, como una franja longitudinal; y por el lado exterior sobresale fuera de la linea de las columnas
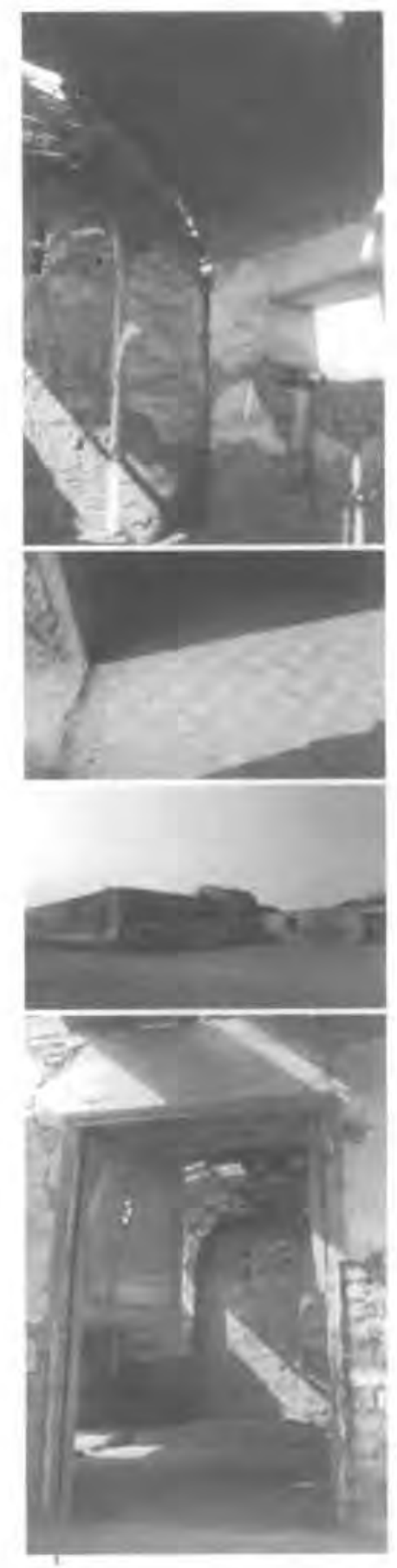


\section{Dr. P. Antonio SAN CRISTÓBAL}

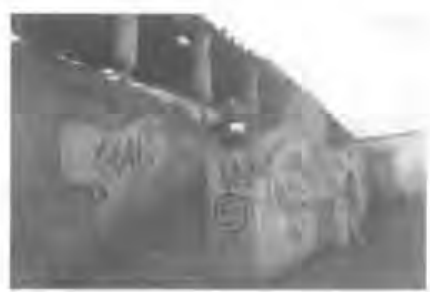

sustentantes del corredor. Resulta además que la sacristía se prolonga más adelante del límite externo en el otro sector corto del corredor lateral localizado a la derecha de la casa.

La sacristía recibió la cubierta plana cuartones, tablas torta de barro comúnmente usada en los aposentos de las casas limeñas. La cubierta de la pequeña capilla es sumamentre interesante por su originalidad. Consiste en una bóveda de medio cañón con una curvatura regular, pero menor que la de media circunferencia, aunque sin formar arco carpanel propiamente dicho ni tampoco un arco rebajado. $\mathrm{La}$ peculiaridad de esta bovedilla no atañe a su tipología, que es la del medio cañón común a muchas otras bóvedas virreinales del periodo barroco; sino que radica en su original sistema constructivo. Notemos que solamente se pudo aplicar esta estructura constructiva debido a la reducida longitud de la navecilla en esta capilla.

Los carpinteros virreinales emplearon las cerchas para labrar las bóvedas de medio cañón armadas con madera, cañas y yeso. Consisten las cerchas en unos tablones aserrados que forman segmentos de circulo, con los cuales, amarrados unos con otros firmemente, se completa un arco de medio punto, o en algún caso un arco carpanel como el que presentan las bóvedas en las trinitarias y El Carmen Alto de Lima.

Una vez formadas las cerchas, se asientan paralelamente sobre muros laterales de la nave a cubrir, dejando cierta distancia de una cercha a otra. Las corchas asi colocadas en sentido vertical se recubren después con las cañas o tablas y el yeso. Pues bien, resulta que la bovedilla de esta capilla de Punchauca no ha sido armada con cerchas curvas, sino con cuartones rectos puestos horizontalmente de peralte. Ejecutaron la terminación curva de un sector menor que la media 
circunferencia en lo alto del muro testero y del muro de los pies en la corta navecilla; y siguiendo la curvatura de estos muros tendieron unos cuartones restos desde un muro al otro paralelo. Las cerchas de las iglesias comunes asientan sobre los muros transversales que son el muro testero y el muro de los pies. Para asegurar la estabilidad de los cuartones restos y alargados distribuidos en forma curva, e impedir su corrimiento hacia abajo, amarraron los cuartones unos con otros mediante unos tirantes transversales de madera introducidos en los extremos y en tres lugares intermedios en la longitud de los cuartones distribuidos equitativamente a distancias proporcionales. El peso de la armadura de las cañas y el yeso, junto con la torta de barro, gravita en esta capilla de Punchauca en sentido transversal a lo que comúnmente acaece en las iglesias con bóvedas de medio cañón labradas con materiales ligeros de madera y yeso. La caparazón de la cubierta carga en Punchauca sobre los cuartones rectos tendidos longitudinalmente $y$ en sentido horizontal desde el muro testero al de los pies; mientras que en las bóvedas comunes limeñas la cobertura pesa sobre las cerchas alineadas transversales a los muros longitudinales paralelos de la nave.

El pequeño retablo de la capilla muestra una estructura muy simple. Por encima de la mesa del altar se alza un banco horizontal con una pequeña hornacina en el centro. El cuerpo único del retablo está conformado por pares de columnas jónicas a cada lado, entre las que se abre la gran hornacina central ahora vacía. Se corona el retablito con una especie informal de frontón de dos pilastrillas, unos roleos laterales y un recuadro arqueado central.

Sería una pena que por abandono llegara a desaparecer totalmente esta hermosa casa-hacienda de Punchauca.

Dr. P. Antonio SAN CRISTÓBAL Miembro de la Academia Nacional de la Historia
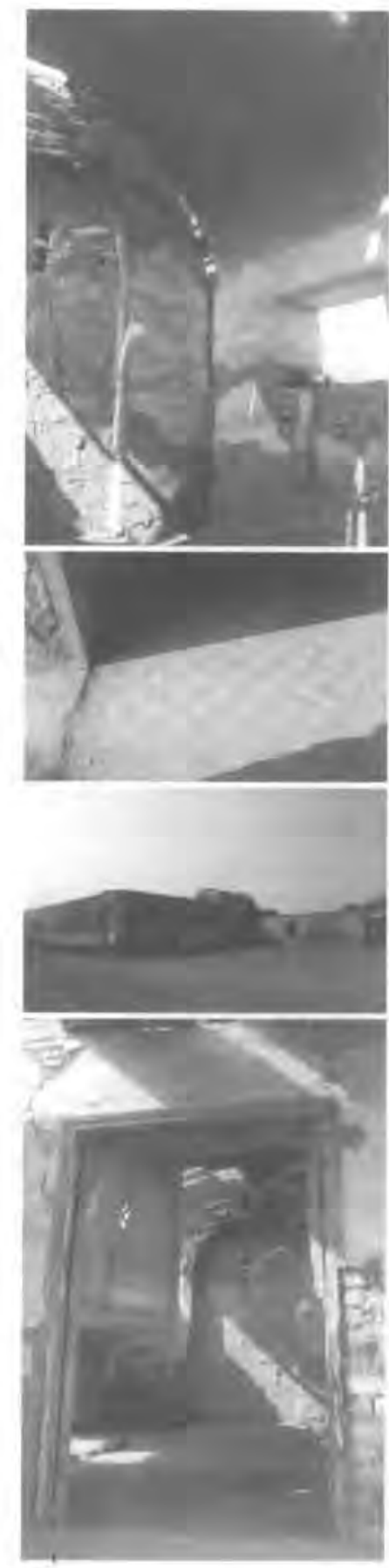